\title{
Neutrophil and eosinophil involvement of the small bowel affected by chronic alcoholism
}

\author{
J F COLOMBEL, R HÄLLGREN, P VENGE, B MESNARD, \\ AND J C RAMBAUD \\ From the Department of Gastroenterology, Lille, France, the Research Unit on Intestinal Function and \\ Nutrition (INSERM 290) Hopital Saint-Lazare, Paris, France, and the Departments of Internal Medicine and \\ Clinical Chemistry, University Hospital, Uppsala, Sweden
}

SUMMARY Excessive ethanol intake may affect the intestinal mucosa functionally and morphologically. The ethanol effect could partly be the result of inflammatory mechanisms, possibly reflected by an enhanced local granulocyte turnover. This study investigated habitual alcoholics by segmental perfusion of the jejunum and analysed the perfusion fluid content of granulocyte granule constituents. The mean jejunal secretion rate of myeloperoxidase (MPO), a neutrophil granule constituent, was $152(26)(\mathrm{SE}) \mathrm{ng} / \mathrm{min} / 40 \mathrm{~cm}$ jejunal segment in the controls $(\mathrm{n}=16)$. The MPO secretion rate in non-cirrhotic habitual alcoholics $(n=7)$ was on average $450(103) \mathrm{ng} / \mathrm{min}$ and significantly increased compared with controls $(\mathbf{p}<\mathbf{0} \cdot 001)$. In contrast alcoholics with cirrhosis $(n=6)$ had normal MPO secretion rate. The mean secretion rate of eosinophil cationic protein (ECP), an eosinophil granule constituent, was in the controls $77(15) \mathrm{ng} / \mathrm{min} / 40 \mathrm{~cm}$ jejunal segment. Corresponding values in non-cirrhotic and cirrhotic alcoholics were $141(38)$ and $130(93) \mathrm{ng} / \mathrm{min}$, respectively (ns). The data suggest an enhanced neutrophil granulocyte turnover in the jejunum in alcoholics, possibly contributing to the ethanol induced affection of the small bowel. The lack of increased neutrophil activity in cirrhotic alcoholics may reflect a role of the liver for granulocyte activity.

Inflammatory lesions of the mucus membranes of the oesophagus and the stomach are often seen in chronic alcoholics. Histologically the presence of neutrophils and/or eosinophils of the superficial lamina propria is a prominent feature of the lesions.' 2 Even though such obvious inflammatory lesions have not been reported in the small intestine, ${ }^{3}$ there is evidence that excessive intake of ethanol may affect the intestinal mucosa. Ultrastructural changes of membranes and of intracytoplastic organelles have been seen during ethanol consumption. ${ }^{+}$Functional abnormalities including malabsorption of nutrients, water, and electrolytes, have also been reported..$^{5-9}$ Ethanol may directly damage the gastro-intestinal mucosa or indirectly because of nutrient depletion. Immunological and inflamatory mechanisms may also con-

Address for correspondence: Dr R Hällgren, Department of Internal Medicine, University Hospital, S-751 85 Uppsala, Sweden.

Received for publication 8 June 1988 tribute to the tissue damage in ethanol induced digestive disease. ${ }^{10-12}$ In an attempt to elucidate the possible presence of enhanced inflammatory activity in the small bowel of habitual alcoholics we have analysed the local intestinal neutrophil and eosinophil activity in alcoholics after a short ethanol withdrawal period. In order to elucidate the influence of liver function on granulocyte activity we included alcoholics with and without liver cirrhosis. The study was done by perfusion of a small bowel segment and analysis of the perfusion fluid for the content of granulocyte granule constituents. Myeloperoxidase (MPO) was measured as a marker for neutrophil turnover ${ }^{13}$ and eosinophil cationic protein (ECP) as a marker for eosinophil turnover. ${ }^{14}$

\section{Methods}

PATIENTS 1656

The control group included 16 patients $(14$ men, 
median age 42 years, range 25-52) who were referred to hospital because of abdominal pain. After complete investigation, including endoscopic biopsies of the proximal jejunum, none of the patients showed evidence of organic disease or immunological abnormality.

Thirteen alcoholics were studied; seven had steatosis $(n=3)$ or steatosis and portal fibrosis $(n=4)$ on liver biopsy; six alcoholics had liver cirrhosis and portal hypertension. Three of the cirrhotic alcoholics were classified ${ }^{15}$ as compensated (class A) and three as decompensated (class B). The alcoholics without cirrhosis were all men (median age 42 years, range 21-55). Their current ethanol consumption was on average $232 \mathrm{~g}$ ethanol/day. The median ethanol withdrawal period was 10 days, range four to 18 days. The alcoholics with liver cirrhosis (five men and one woman) had a median age of 59 years, range 30-69. Their current consumption was on average $220 \mathrm{~g}$ ethanol/day. The median ethanol withdrawal period was seven days, range three to 14 . All patients had at least four endoscopic biopsies of the proximal jejunum.

\section{JEJUNAL PERFUSION}

Segmental perfusion of the jejunum was performed according to Rambaud et al,${ }^{16}$ using a four lumen tube with a proximal occluding balloon. The length of the test segment was $40 \mathrm{~cm}$. The tube was swallowed by the subject before dinner and the perfusion started after overnight fasting; the infusion point being located near the duodenojejunal junction under the inflated balloon (checked fluoroscopically). The gut was perfused with a $115 \mathrm{mmol} \mathrm{NaCl}, 10 \mathrm{mmol} \mathrm{KCl}$, and $35 \mathrm{mmol}$ mannitol solution containing $1 \mathrm{~g} / \mathrm{l}$ of polyethylene glycol 4000 (PEG), at a rate of $10 \mathrm{ml} /$ minute. Four consecutive 20 minutes samples were collected after a 60 minutes equilibration period. Perfusate samples were recovered at $0^{\circ} \mathrm{C}$. One millimole diisoprophylfluorophosphate, a potent protease inhibitor, was added to an aliquot of each sample which was stored at $-20^{\circ} \mathrm{C}$ until assayed. Previous studies with the same technique have shown that the coefficient of variations of secretion rates of water, electrolytes and various endogenous proteins were mild.${ }^{17}$ Thus, in the present experiments, one or two 20 minute samples chosen in a random order were used for analytical procedure for each subject.

During perfusion, duodenal contents proximal to the balloon were continuously collected and discarded. Contamination of the jejunal samples by duodenal fluid bypassing the balloon was controlled by using two semiquantitative methods: detection of bromosulphophthalein, which was infused above the balloon into the duodenum, and detection of chymotrypsin and lipase activity in the perfusate.
Any contaminated sample was discarded after detection. Absence of blood contamination was confirmed in all samples (Hemotest, Ames, France).

ANALYTICAL METHODS

Myeloperoxidase and ECP were measured by radioimmunoassays. ${ }^{1814}$ The jejunal fluid samples were analysed in duplicate and in sequence. The sensivity for the MPO assay was $4 \mu \mathrm{g} / \mathrm{l}$ and for the ECP assay $2 \mu \mathrm{g} / \mathrm{l}$. The variability was less than $10 \%$ for both methods. Parallel standard curves were obtained for both proteins by means of the respective protein standards mixed with either buffer or a constant volume of jejunal perfusion fluid. Albumin in jejunal perfusion fluid was measured by fluorescence nephelometry (Multistat III, Instrumental, Lexington, MA) at the Department of Clinical Chemistry, University Hospital of Uppsala. Polyethylene glycol was assayed by the turbidic method of Hydén."

STATISTICAL ANALYSIS

Water, MPO, and ECP flow rates at the sampling point, and thus the secretion of MPO and ECP in the test segment were calculated according to the usual formulae. ${ }^{12}$ When two samples were analysed in a subject, the arithmetic mean of each parameter measured was used for calculation. Statistical comparisons between controls and patients were done by $t$ test.

\section{Results}

The MPO concentration in the jejunal perfusion fluid from the controls $(n=16)$ was on average $15(2 \cdot 5)$ (SE) $\mu \mathrm{g} / \mathrm{l}$, actual range 4-38. In habitual alcoholics without liver cirrhosis $(n=7)$ the perfusion fluid MPO concentration was increased $(\mathrm{p}<0.001)$; mean MPO was $46(10.3) \mu \mathrm{g} / \mathrm{l}$, actual range 20-92. Alcoholics with liver cirrhosis $(n=6)$ had as a group similar levels as the controls, mean MPO was 19 (13). One of the cirrhotic patients had an MPO concentration $(84$ $\mu \mathrm{g} / \mathrm{l})$ above the reference range.

The ECP concentration in the jejunal perfusion fluid from the controls was on average $8.5(1.6) \mu \mathrm{g} / \mathrm{l}$, actual range 1.5-24. The ECP concentration in perfusion fluid from alcoholics without liver cirrhosis was $15(3.9) \mu \mathrm{g} / \mathrm{l}$, actual range 2-28 and in alcoholics with cirrhosis $13.6(9.8) \mu \mathrm{g} / \mathrm{l}$, actual range $1-63$. The observed increases of the ECP concentrations in the alcoholic groups did not reach statistical significance.

The albumin concentration in perfusion fluid was in the control group $15 \cdot 2(5 \cdot 4) \mathrm{mg} / \mathrm{l}$. Similar concentration of albumin was seen in alcoholics with cirrhosis, $16 \cdot 2(3 \cdot 1) \mathrm{mg} / \mathrm{l}$, while alcoholics without cirrhosis had increased albumin concentration, 38 


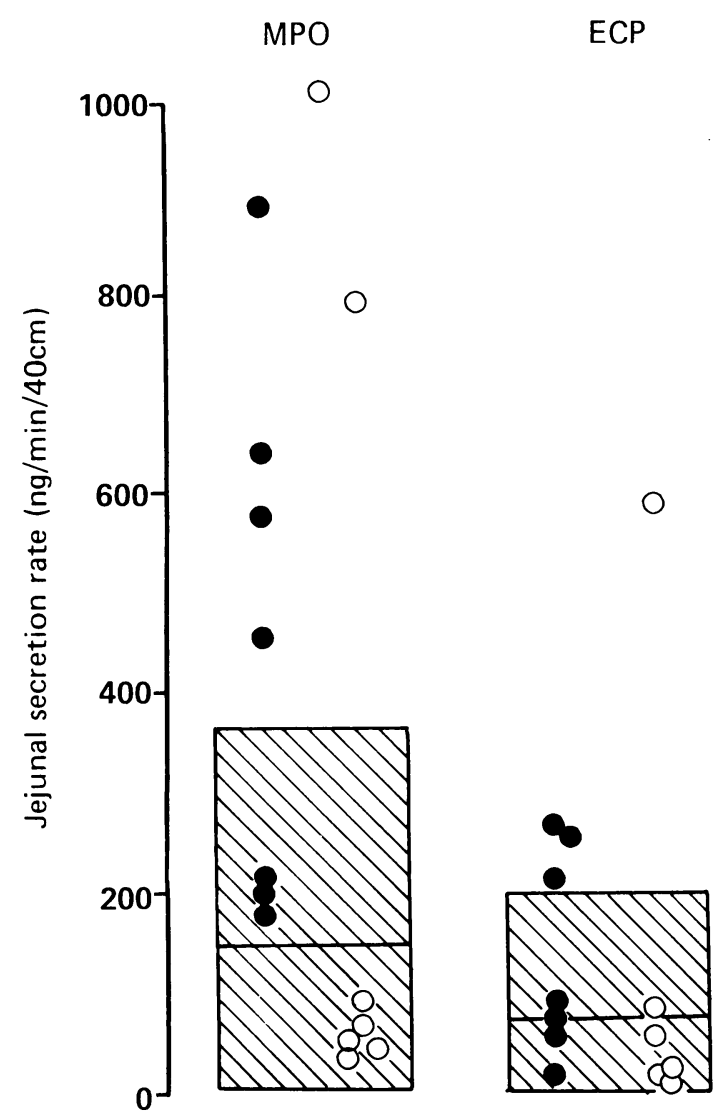

Fig. 1 The jejunal secretion rates of myeloperoxidase (MPO) and eosinophil cationic protein (ECP) in noncirrhotic alcoholics (filled circles) and alcoholics with liver cirrhosis (open circles). The shaded areas represent the $2 S D$ ranges for the secretion rates of $M P O$ and ECP in controls $(n=16) ;$ their mean secretion rates are indicated as well.

$(8.9) \mathrm{mg} / \mathrm{l}(\mathrm{p}<0 \cdot 05)$. The jejunal biopsy specimens were all normal in the alcoholics and there was no apparent infiltration of granulocytes.

The flow rates during intestinal perfusion were in the control group $9 \cdot 3(0 \cdot 1)(\mathrm{SE}) \mathrm{ml} / \mathrm{min}$, in alcoholics without cirrhosis $9 \cdot 7(0 \cdot 2)$, and cirrhotic alcoholics $9 \cdot 8(0 \cdot 1)$. In order to compensate for differences in flow rate the secretion rates of MPO and ECP were calculated. The mean secretion rate of MPO in the control group was $152(26) \mathrm{ng} / \mathrm{min} / 40 \mathrm{~cm}$ (SE) jejunal segment. Corresponding values for the non-cirrhotic and the cirrhotic alcoholics were $450(103)(p<0.001)$ and 181. (123) $(\mathrm{p}>0 \cdot 05)$, respectively. The mean secretion rate of ECP in the control group was 77 (15) $\mathrm{ng} / \mathrm{min} / 40 \mathrm{~cm}$ jejunal segment, corresponding values in non-cirrhotic and cirrhotic alcoholics were 141 (38) and $130(93)(p>0.05)$, respectively. The individual secretion rates of the alcoholics are presented in the
Figure. Four of seven non-cirrhotic alcoholics and one in six cirrhotic alcoholics had MPO secretion rates above the reference range. Slightly increased secretion rate of ECP was observed in four of 13 of all alcoholics.

The current ethanol consumption was not related to the MPO or ECP secretion rates. The MPO secretion rate tended to increase with the length of abstinence period in the non-cirrhotic alcoholics but did not reach statistical significance $(r=0 \cdot 61, p=0 \cdot 1)$.

\section{Discussion}

The main findings of the present study are the significantly increased concentrations of MPO, a neutrophil granule constituent, ${ }^{1.3}$ in the jejunal perfusion fluid of habitual alcoholics. The increase was on average about three times compared with the MPO concentrations in a control population. In contrast, the jejunal perfusion fluid concentrations of ECP, a specific granule constituent of eosinophils, ${ }_{1+2122}$ were more modestly increased in alcoholics. These findings might suggest an increased, non-activated neutrophil mass or, alternatively a normalised but activated granulocyte mass in the intestinal wall. It seems less likely that the measured concentrations of MPO and ECP merely is a consequence of passive penetration through the blood-mucus membrane barrier. In fact, the circulating concentrations of ECP in health ${ }^{14}{ }^{19}$ are close to the measured perfusion fluid concentrations of ECP; the circulating MPO are about 10 times higher than the jejunal fluid concentrations. ${ }^{18}$ In contrast the blood:perfusate ratio of albumin is about 1:2000. Furthermore, habitual alcoholics have normal serum concentrations of ECP and only marginally increased concentrations of lactoferrin, another granulocyte granule constituent. ${ }^{3.3}$ Because alcoholics had signs of increased albumin leakage to the intestine, however, it cannot be excluded that damage to the barrier has influenced the results to some extent.

Myeloperoxidase occurs in the azurophil granules of neutrophils and is together with other granule enzymes delivered into the phagocytic vacuole when degranulation occurs. During this process and during chemotactic movement the granulocyte also release granule constituents externally. ${ }^{13}$ As with neutrophils, eosinophil phagocytosis and chemotaxis is followed by secretion of granule proteins. The granulocyte granule constituents fulfill a central role in the combat against invading microorganisms - for example, MPO can use hydrogen peroxidase in the presence of either $\mathrm{I}^{-}$or $\mathrm{CI}$ to kill bacteria. ${ }^{13}$ The major eosinophil granula constituents, ECP, major basic protein and eosinophil peroxidase, are highly cytotoxic useful in the protection against parasites. ${ }^{2+2}$ 
The destructive mechanisms induced by neutrophil and eosinophil granule products, however, might also be turned against the host and be involved in the development of inflammatory organ lesions. We have recently noticed when using the same perfusion technique as described in this study, that patients with Crohn's disease and coeliac disease have similar jejunal fluid concentrations of MPO as alcoholics without liver cirrhosis (Hällgren et al, to be published). The ECP concentrations measured in alcoholics were approximately the same magnitude as those observed in patients with Crohn's disease while patients with coeliac disease had much higher ECP concentrations in the perfusion fluid. In these inflammatory bowel diseases we have reason to suspect that an active granulocyte degranulation, as part of the local inflammatory response, underlies the observed increase of granule constituents in the jejunal perfusion fluid.

The hypothesis that increased jejunal fluid concentrations of above all MPO might reflect a neutrophil dominated inflammatory reaction was not supported by examination of jejunal biopsy specimens from the alcoholics as the biopsies showed no apparent infiltration of granulocytes. This might reflect that jejunal perfusion studies are in fact a more sensitive technique for detecting low active inflammatory reactions. The observation that non-cirrhotic habitual alcoholics had more obvious signs of an enhanced neutrophil turnover in the small bowel than alcoholics with ethanol induced liver cirrhosis may suggest that impaired liver function depresses granulocyte activity. In fact, previous studies have shown defective granulocyte chemotaxis associated with a serum inhibitor in patients with alcoholic liver cirrhosis. ${ }^{26}{ }^{27}$ The observed lack of enhanced granulocyte turnover in the small bowel of cirrhotic alcoholics in spite of excessive ethanol intake might illustrate a defect in their local inflammatory response, possibly of relevance for their unique tendency to develop bacteraemia, particularly with organisms from the gastrointestinal tract.

This study was supported by grants from the Swedish Medical Research Council.

\section{Refp 'onces}

1 Seefeld U, Krejs GJ, Siebenmann RE, Blum AL. Esophageal histology in gastroesophageal reflux. $\mathrm{Am} \mathrm{J}$ Dig Dis 1977; 22: 956-64.

2 Palmer ED. Erosive gastritis in cirrhosis. Am J Dig Dis 1957; 2: 31-7.

3 Jian R, Modigliani R. Absorption intestinale et alcoolisme chez l'homme. Gastroenterol Clin Biol 1980; 4: $577-87$.
4 Rubin E, Rybak BJ, Lindenbaum J, Gerson CD, Walker G, Lieber CS. Ultrastructural changes in the small intestine induced by ethanol. Gastroenterology 1972; 63: 801-14.

5 Halsted CH, Robles E, Mezey E. Intestinal malabsorption in folate-deficient alcoholics. Gastroenterology 1973; 64: 526-32.

6 Krasner N, Cochran KM, Russel RI, Carmichael HA, Thompson GG. Alcohol and absorption from the small intestine 1. Impairment of absorption from the small intestine in alcoholics. Gut 1976; 17: 24.5-8.

7 Mekhjian HS, May ES. Acute and chronic effects of ethanol and fluid transport in the human intestine. Gastroenterology 1977: 72: 1280-6.

8 Halsted CH. Robles EA, Mezeye E. Decreased jejunal uptake of labelled folic acid (H-PGA) in alcoholic patients: roles of alcohol and nutrition. $N$ Engl J Med 1971; 285: 701-6.

9 Wilson FA. Hoyumpa AM. Ethanol and small intestinal transport. Gastroenterology 1979; 76: 388-403.

10) Paronetto F. Immunological factors in alcohol liver disease. Semin Liver Dis 1981; 1: 232-43.

11 Kanagasunderam N, Lecvy CM. Ethanol, immune reactions and the digestive system. Clin Gastroenterol 1981; 10: 295-306.

12 MacSween RNM. Alcohol and liver injury: genetic and immunologic factors. Acta Med Scand 1984; 703: 57-65.

13 Klebanoff SJ. Antimicrobial mechanisms in neutrophilic polymorphonuclear leukocytes. Semin Hematol 1975; 12: 117-42.

14 Venge P. Dahl R. Fredens K. Hällgren R. Eosinophil cationic proteins in health and disease. In: Yoshida T. Torisu M. eds. Immunobiology of the eosinophil. New York: Elsevier Science Publishing Co, 1982: 163-77.

15 Pugh RNH, Murray-Lyon IM, Dawson JL, et al. Transection of the oesophagus for bleeding oesophageal varices. Br J Surg 1973; 60: 646-9.

16 Rambaud JC, Duprey F, Nouel O, Hostein J, Delpech B. Bernier JJ. Assessment of the accuracy of segmental perfusion under an occluding balloon for measuring the intrajejunal secretion of albumin and immuno-globulin A. Gut 1981; 22: 371-5.

17 Jonard PP, Rambaud JC, Dive C, Vacrman JP. Galian A. Delacroix DL. Secretion of immunoglobulins and plasma proteins from the jejunal mucosa. Transport rate and origin of polymeric immunoglobulin A.J Clin Invest 1984; 74: 525-35.

18 Olofsson T, Olsson I, Venge P. Elgefors B. Serum myeloperoxidase and lactoferrin in neutropenia. Scand J Haematol 1977; 18: 73-80.

19 Venge P, Roxin L-E, Olsson I. Radioimmunoassay of human cosinophil cationic protein. Br J Haematol 1977; 37: $331-6$.

20) Hyden SA. A turbidic method for the determination of the higher polyethylene glycols in biological materials. Ann R Agricul Coll 1955; 22: 139-45.

21 Olsson I, Venge P, Spitznagel JK, Lehrer R. Argininerich cationic proteins of human eosinophil granules. Comparison of the constituents of eosinophilic and neutrophilic leukocytes. Lab Invest 1977; 36: 493-5()).

22 Tai P-C, Spry CJF, Peterson C, Venge P, Olsson I. Monoclonal antibodies distinguish between storage and 
secreted forms of eosinophil cationic protein. Nature 1984; 309: 182-4.

23 Lundin L, Hällgren R, Venge P. Sequential studies on serum levels of lysozyme, lactoferrin and eosinophil cationic protein in alcoholics after alcohol withdrawal. Scand J Haematol 1980; 25: 431-8.

24 McLaren DJ, Peterson CGB, Venge P. Schistosoma Mansoni: further studies on the interaction between schistosomula and granulocyte-derived cationic protein in vitro. Parasitology 19; 88: 491-503.
25 Butterworth AE, Wassom DL, Gleich CJ, Loegering DA, David JR. Damage to schistosomula of schistosoma mansoni induced by eosinophil major basic protein. J Immunol 1979; 122: 221-5.

26 DeMco AN, Andersen BR. Defective chemotaxis associated with a serum inhibitor in cirrhotic patients. $N$ Engl J Med 1972; 286: 735-40.

27 Van Epps DE, Strickland RG, Williams RC. Inhibitors of leukocyte chemotaxis in alcoholic liver disease. Ann Intern Med 1975; 59: 200-7. 